\title{
Evaluation of COVID-19 Disease and the Effect of Trends in Intervention Measures: The Pediatric Perspective from a Tertiary Care Hospital in Turkey
}

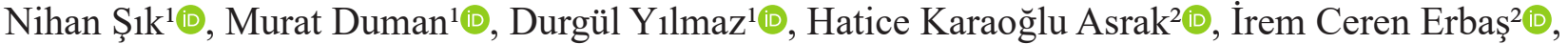

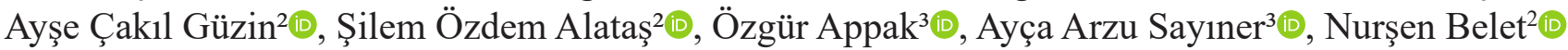

${ }^{1}$ Division of Pediatric Emergency Care, Department of Pediatrics, Dokuz Eylül University School of Medicine, İzmir, Turkey ${ }^{2}$ Division of Pediatric Infectious Diseases, Department of Pediatrics, Dokuz Eylül University School of Medicine, İzmir, Turkey

${ }^{3}$ Department of Medical Microbiology, Dokuz Eylül University School of Medicine, İzmir, Turkey

Background: COVID-19 is an emerging disease of global public health concern.

Aims: To evaluate the epidemiological, clinical, laboratory, and radiologic findings and the clinical outcomes of children who were diagnosed with SARS-CoV-2 by polymerase chain reaction (PCR), and to evaluate the effect of the trends in intervention measures.

Study Design: Between April 2, 2020 and January 16, 2021, children aged 0-18 years who had presented at the pediatric emergency department and were diagnosed with confirmed SARS-CoV-2 by PCR were enrolled.

Methods: Details on demographics, epidemiologic characteristics, clinical findings, laboratory data, and radiologic investigations, hospital admissions, and prognosis were recorded. According to clinical severity, patients were divided into 5 groups as asymptomatic, mild, moderate, severe, or critical. We classified the outbreak into 3 periods. The first was between April 2, 2020, the date when the first pediatric case of our hospital was detected, and June 1, 2020, when restrictive measures were relaxed. The second period was between June 1, 2020 and November 15, 2020, when restrictive measures were reimplemented. The third period was between November 15, 2020 and January 16, 2021.
Results: A total of 600 patients [median age: 10.3 years (IQR: 4.4-15.1); 304 females] were enrolled. Among them, $25.0 \%$ were asymptomatic, while the 3 most common symptoms among symptomatic cases were fever, cough, and fatigue. There was contact with a COVID-19 PCRpositive individual in $73.5 \%$ of the cases, with $76.6 \%$ of those being a household contact. There were $23(3.9 \%)$ moderate, severe, or critical cases in terms of clinical severity. The presence of chronic disease, a pathological physical chest examination, and procalcitonin levels of $>0.05 \mathrm{ng} / \mathrm{mL}$ were identified as predictors of being moderate, severe, or critical. Twenty-four $(4.0 \%)$ patients were admitted to the hospital; 14 $(2.3 \%)$ to the ward and $10(1.6 \%)$ to the pediatric intensive care unit. In the second intervention period, we observed a rapidly increasing number of new cases daily, especially in August. From September, an increase was observed, being particularly marked from October to November 18 . Since then, there was a decrease in the daily number of cases.

Conclusion: The majority of the cases were asymptomatic or had a mild clinical presentation. The presence of chronic disease, a pathological physical chest examination, and procalcitonin levels of $>0.05 \mathrm{ng} / \mathrm{mL}$ were identified as predictors of being moderate, severe, or critical in terms of clinical severity. Strict intervention measures seem to be effective in containing the spread of COVID-19.

\section{INTRODUCTION}

In December 2019, an unknown type of coronavirus, which was identified "severe acute respiratory syndrome coronavirus-2" (SARS-CoV-2), was detected in China. The SARS-CoV-2-related disease was named COVID-19 disease and it was declared a pandemic by the World Health Organization (WHO) on March 11, 2020. COVID-19 is an emerging disease of global public health concern and it is regarded as a pandemic; in terms of global prevention and control strategies, huge challenges still remain. ${ }^{1,2}$

\footnotetext{
Address for Correspondence: Murat Duman, Division of Pediatric Emergency Care, Department of Pediatrics, Dokuz Eylül University School of Medicine, İzmir, Turkey e-mail: mduman@deu.edu.tr

Received: March 8, 2021 Accepted: May 7, 2021 • DOI: 10.5152/balkanmedj.2021.21045

Available at www.balkanmedicaljournal.org

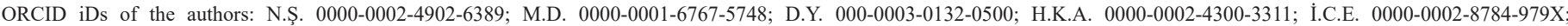
A.Ç.G. 0000-0003-0023-4758; Ş.Ö.A. 0000-0002-2662-5039; Ö.A. 0000-0003-1810-8346; A.A.S. 0000-0001-6750-2353; N.B. 0000-0002-1513-1797.

Cite this article as:

Ş1k N, Duman M, Y1lmaz D, et al. Evaluation of COVID-19 disease and the effect of trends in intervention measures: The pediatric perspective from a tertiary care hospital in Turkey. Balkan Med J. 2021;38(4):222-228.

Copyright@Author(s) - Available online at http://balkanmedicaljournal.org/
} 
To prevent the disease from entry and spread in Turkey, various preventive measures were implemented in accordance with the recommendations of WHO. Restrictive measures included flight restrictions to certain countries, which gradually expanded to suspending all flights and prohibiting the entry of foreign nationals, as well as 14-day isolation and symptom monitoring for people who came from countries under risk. Those with chronic illnesses were granted administrative leave, and in-person attendance at schools and public leisure and entertainment activities were temporarily suspended. Special measures were implemented for penitentiary institutions, dormitories, nursing homes, and public transport. A curfew was implemented for citizens of $>65$ years and $<20$ years of age, which continued at certain times on weekdays and weekends. Preventive measures were implemented to cover society as a whole. Considering the decrease in the number of COVID-19 PCR-positive cases, the restrictive measures were relaxed as of June 1, 2020, in Turkey. This relaxation continued until November 15, 2020, and, since then, restrictive measures have been re-implemented due to the increase in the number of COVID-19 PCR-positive cases. ${ }^{3}$

The first case was detected on March 10, 2020 in Turkey, and the first pediatric case in our hospital was seen on April 2, 2020. In pediatric cases, the course of the disease ranges from mild upper respiratory tract infection to severe disease, in which the dyspnea occurs with central cyanosis and the oxygen saturation level is $<92 \%$, with other hypoxia manifestations. In general, children have been less affected than adults in terms of severity. ${ }^{4}$ However, a recent finding was described as multisystem inflammatory syndrome in children (MIS-C), which was associated with recent infection or exposure to SARS-CoV-2, suggesting that the pediatric population may also suffer from distinctive consequences of this infection.,

In this study, we aimed to evaluate the epidemiological, clinical, laboratory, and radiologic findings, as well as the treatment and clinical outcomes of pediatric patients diagnosed with SARS-CoV-2 by PCR; to determine the incidence and risk factors of the disease; and to evaluate the effect of the trends in intervention measures.

\section{MATERIAL AND METHODS}

This was a cross-sectional study which was performed in the pediatric emergency department of a tertiary hospital with approximately 120000 pediatric emergency department visits annually. The study was approved by the local ethics committee.

Children aged 0-18 years who had presented at the pediatric emergency department between April 2, 2020 and January 16, 2021, and were diagnosed with confirmed SARS-CoV-2 reverse transcription by PCR (with a nasopharyngeal/tracheal specimen) or with serum-specific antibodies against SARS-CoV-2, based on the guidelines published by the Turkish Ministry of Health's Scientific Committee on COVID-19 (which have been revised intermittently according to the recommendations of the Coronavirus Scientific Advisory), ${ }^{3}$ or diagnosed with MIS-C using the US Centers for Disease Control and Prevention (CDC) criteria, were included in the study. ${ }^{7}$ We used the International Classification of Diseases codes for COVID-19 and MIS-C to identify patients' diagnosis.
We obtained information from the computer database, electronic medical records, medical charts, and nursing records. Patients who were diagnosed or treated in another facility and those with insufficient data were excluded. Demographics, presence of chronic illness, symptoms with duration, history of contact with suspected/ confirmed COVID-19 cases, time from contact to onset of symptoms, and complaints of the contacts were recorded. As symptoms such as sore throat or diminished or loss of taste and smell perception cannot be described by infants and preschool-aged children, only children who were aged over 3 years were asked about sore throat and those over 5 years were asked about diminished or loss of taste and smell perception. Patients were divided into 4 age groups as $\leq 1$ year, 1-6 years, 6-10 years, and $>10$ years. Clinical findings, laboratory data, and the results of radiologic investigations were recorded. Age-adjusted tachycardia was recorded using published heart rate norms for children. ${ }^{8}$ Lymphopenia was recorded using published lymphocyte count norms according to age groups. C-reactive protein, procalcitonin, D-dimer, and troponin levels were divided into 2 groups according to the cut-off values of the laboratory as follows: $\leq 5 \mathrm{mg} / \mathrm{L}, \leq 0.05 \mathrm{ng} / \mathrm{mL}, \leq 0.55 \mu \mathrm{g} / \mathrm{mL}$, and $42.8 \mathrm{mg} / \mathrm{L}$, or higher. According to clinical severity, patients were divided into 5 groups as asymptomatic, mild, moderate, severe, or critical, as previously described. ${ }^{9}$ The asymptomatic and mild cases were considered as Group 1, and the moderate, severe, and critical cases as Group 2. Need for respiratory support, ward/intensive care unit admission, length of stay in the hospital, and prognosis were recorded. To better reflect the epidemiological characteristics of COVID-19 disease and the corresponding interventions, we classified the outbreak into 3 periods. The first period was that between April 2, 2020, when the first pediatric case was detected in our hospital, and June 1, 2020, when restrictive measures were relaxed. The second period was between June 1, 2020 and November 15, 2020, when restrictive measures were re-implemented. Finally, the third period was between November 15, 2020 and January 16, 2021.

\section{Statistical Analysis}

All statistical analyses were performed using SPSS 22.0 for Windows (IBM SPSS Corp., Armonk, NY, USA). Categorical and continuous variables were reported as frequencies and percentiles and as means with standard deviations (SDs) or medians with interquartile ranges (IQRs). The Mann-Whitney $U$-test and the Kruskal-Wallis test were used to compare non-parametric variables, and the Student's $t$-test and one-way analysis of variance were used for parametric data. For the comparison of groups, categorical variables were analyzed with a Chi-square test. Multivariate analysis was performed using logistic regression to determine predictors of clinical severity. A value of $P<.05$ was considered statistically significant.

\section{RESULTS}

During the study period, a total of 53765 PCR tests were performed with 6601 adults and 600 children being found PCR-positive for COVID-19. The ratio of adult cases to pediatric cases was 9.0\%. The median age was 10.3 years (IQR: 4.4-15.1), and 304 
cases were female $(50.7 \%)$. Sixty-two $(10.3 \%)$ of the patients had chronic illnesses. Of the patients, $150(25.0 \%)$ were asymptomatic; the 3 most common symptoms were fever $(n=272 ; 45.3 \%)$, cough $(n=179 ; 29.8 \%)$, and fatigue $(n=124 ; 20.7 \%)$. Among 272 children with fever, $171(62.8 \%)$ presented with a fever between 37.7 and $38.0^{\circ} \mathrm{C}$. There was contact with a COVID-19 PCR-positive individual in $441(73.5 \%)$ of the cases, with $338(76.6 \%)$ of these being household contact. The median time for onset of symptoms of the patients after contact was 4.0 days (IQR: 3.0-6.0). The most common complaints of the individuals with whom there was contact were cough $(56.7 \%)$, fever $(45.0 \%)$, and fatigue $(44.7 \%)$. The households of $370(61.7 \%)$ children were in quarantine (Table 1).

In $190(31.7 \%)$ cases, laboratory tests were obtained. Among them, lymphopenia was found in $55(28.9 \%)$ of the cases. Elevated levels of procalcitonin in $69(35.8 \%)$ cases, C-reactive protein (CRP) in $72(37.4 \%)$ cases, D-dimer in $65(34.2 \%)$ cases, and troponin in $6(3.2 \%)$ cases were seen, when compared to the reference values (Table 2). Chest radiography was performed for 129 $(21.5 \%)$ patients; $117(90.6 \%)$ were evaluated as normal, while consolidation was reported in 5 patients, bronchovascular change in 4 patients, diffuse patch involvement in 3 patients, and pleural effusion in 1 patient. Thorax computed tomography (CT) was performed for 23 (3.8\%) cases; 14 patients had normal CT findings, 6 patients had peripheral ground-glass appearance, 3 patients had consolidation, and 1 patient had pleural effusion.

Considering symptomatic cases, the most common diagnoses were upper respiratory system infection ( $n=389,64.8 \%$ ), followed by acute gastroenteritis $(n=38,6.3 \%)$. There were $7(1.2 \%)$ patients who needed respiratory support, and among them, 3 underwent intubation, 3 underwent high-flow nasal cannula oxygen therapy, and 1 received oxygen by a simple face mask. Among these 7 cases, 6 were admitted to the pediatric intensive care unit (PICU).

According to clinical severity, there were 577 (96.1\%) patients in the asymptomatic-mild group (Group 1) and 23 (3.9\%) in the moderate-severe-critical group (Group 2). The most common age group in Group 2 was $>10$ years $(56.5 \%)$, followed by the age group of $\leq 1$ year $(21.7 \%)$. Group 2 had more males and a higher percentage of chronic illnesses than Group $1(P<.05)$. Symptoms of vomiting, pathological respiratory system examination, and tachypnea were higher in Group 2 than in Group 1, and levels of CRP, procalcitonin, prothrombin time (PT), D-dimer, international normalized ratio (INR), troponin, and ferritin were also higher in Group 2 (Table 3). When we evaluated presence of chronic diseases, symptoms of vomiting, tachypnea, and levels of CRP, procalcitonin, PT, D-dimer, INR, troponin, and ferritin, the presence of chronic diseases $(\mathrm{OR}=6.400,95 \% \mathrm{CI}: 1.467-12.126, P=011)$, pathological respiratory system examination $(\mathrm{OR}=10.100,95 \% \mathrm{CI}$ : $2.108-40.020, P=.001$ ), and procalcitonin levels of $>0.05 \mathrm{ng} / \mathrm{mL}$ $(\mathrm{OR}=9.300,95 \% \mathrm{CI}: 1.672-19.504, P=0.002)$ were identified as predictors of being moderate, severe, or critical, according to clinical severity.

Twenty-four (4.0\%) patients were admitted to the hospital: 14 $(2.3 \%)$ to the ward and $10(1.6 \%)$ to the PICU (Table 1$)$. The
TABLE 1. Demographics, Clinical Findings, Clinical Severity, and Prognosis of the Patients in the Study

\begin{tabular}{|c|c|}
\hline Variable & $N=600$ \\
\hline Female gender, $n(\%)$ & $304(50.7)$ \\
\hline Age in years, median (IQR) & 10.3 (IQR: 4.4-15.1) \\
\hline \multicolumn{2}{|l|}{ Age group, $n(\%)$} \\
\hline $0-1$ year & $42(7.0)$ \\
\hline $1-6$ years & $136(22.7)$ \\
\hline $6-10$ years & $99(16.5)$ \\
\hline$>10$ years & $323(53.8)$ \\
\hline Underlying disease, $n(\%)$ & $62(10.3)$ \\
\hline $\begin{array}{l}\text { Contact with a COVID-19 PCR-positive } \\
\text { individual, } n(\%)\end{array}$ & $441(73.5)$ \\
\hline Household, $n(\%)$ & $338(76.6)$ \\
\hline \multicolumn{2}{|l|}{ Body temperature $\left({ }^{\circ} \mathrm{C}\right), n(\%)$} \\
\hline$\leq 37.5$ & $324(53.8)$ \\
\hline $37.6-38.0$ & $171(28.5)$ \\
\hline $38.1-39.0$ & $102(17.0)$ \\
\hline$>39.0$ & $3(0.5)$ \\
\hline \multicolumn{2}{|l|}{ Symptoms, $n(\%)$} \\
\hline Fever & $272(45.3)$ \\
\hline Cough & $179(29.8)$ \\
\hline Fatigue & $124(20.7)$ \\
\hline Sore throat & $100(16.7)$ \\
\hline Headache & $69(11.5)$ \\
\hline Runny nose & $61(10.2)$ \\
\hline Taste/smell loss & $47(7.8)$ \\
\hline Myalgia & $41(6.8)$ \\
\hline Diarrhea & $32(5.3)$ \\
\hline Nausea/vomiting & $22(37)$ \\
\hline Abdominal pain & $19(3.2)$ \\
\hline Respiratory distress & $9(1.5)$ \\
\hline Chest pain & $5(0.8)$ \\
\hline $\begin{array}{l}\text { Time between contact and symptoms (days), } \\
\text { median (IQR) }\end{array}$ & $4.0(3.0-6.0)$ \\
\hline \multicolumn{2}{|l|}{ Household, $n(\%)$} \\
\hline In quarantine & $370(61.7)$ \\
\hline Admitted to the ward & $45(7.5)$ \\
\hline Admitted to the intensive care unit & $8(1.3)$ \\
\hline Exitus & $1(0.2)$ \\
\hline Tachycardia, $n(\%)$ & $8(1.3)$ \\
\hline Abnormal physical chest examination, $n(\%)$ & $15(2.5)$ \\
\hline \multicolumn{2}{|l|}{ Clinical severity, $n(\%)$} \\
\hline Asymptomatic & $150(25.0)$ \\
\hline Mild & $435(72.5)$ \\
\hline Moderate & $18(3.0)$ \\
\hline Severe & $4(0.7)$ \\
\hline Critical & $1(0.2)$ \\
\hline Hospital admission, $n(\%)$ & $24(4.0)$ \\
\hline PICU admission, $n(\%)$ & $10(1.6)$ \\
\hline Length of stay in PICU (days), median (IQR) & $7.5(3.1-15.1)$ \\
\hline Length of stay in hospital (days), median (IQR) & $8.5(6.0-14.2)$ \\
\hline Mortality, $n(\%)$ & $2(0.3)$ \\
\hline
\end{tabular}

$\mathrm{SD}$, standard deviation; IQR, interquartile range; PICU, pediatric intensive care unit. 
TABLE 2. Laboratory and Radiologic Investigations of the Patients in the Study

\begin{tabular}{|c|c|}
\hline Variable & $n=600$ \\
\hline Laboratory tests, $n(\%)$ & $190(31.7)$ \\
\hline Lymphopenia, $n(\%)$ & $55(32.1)$ \\
\hline Hemoglobin $(g / d L)$, mean \pm SD $(\min -\max )$ & $12.8 \pm 1.6(11.8-13.9)$ \\
\hline Platelet count $/ \mathrm{mm}^{3}$, median (IQR) & $265500.0(221500.0-312500.0)$ \\
\hline Prothrombin time (s), median (IQR) & $12.0(11.5-12.5)$ \\
\hline $\begin{array}{l}\text { Activated partial thromboplastin time (s), } \\
\text { median (IQR) }\end{array}$ & $31.0(28.6-33.3)$ \\
\hline $\begin{array}{l}\text { International normalized ratio, median } \\
\text { (IQR) }\end{array}$ & $1.0(0.9-1.0)$ \\
\hline Fibrinogen (mg/dL), median (IQR) & $3.2(2.6-3.6)$ \\
\hline D-dimer $(\mu \mathrm{g} / \mathrm{mL})$, median (IQR) & $0.4(0.3-1.1)$ \\
\hline D-dimer $>0.55 \mu \mathrm{g} / \mathrm{mL}, n(\%)$ & $65(40.4)$ \\
\hline C-reactive protein $(\mathrm{mg} / \mathrm{L})$, median $(\mathrm{IQR})$ & $3.7(0.9-9.1)$ \\
\hline C-reactive protein $>5 \mathrm{mg} / \mathrm{L}, n(\%)$ & $72(40.2)$ \\
\hline Procalcitonin (ng/mL), median (IQR) & $0.05(0.02-0.09)$ \\
\hline Procalcitonin $>0.05 \mathrm{ng} / \mathrm{mL}, n(\%)$ & $69(46.0)$ \\
\hline Troponin (mg/L), median (IQR) & $5.0(5.0-5.0)$ \\
\hline Troponin $>42.8 \mathrm{mg} / \mathrm{L}, \mathrm{n}(\%)$ & $6(4.3)$ \\
\hline Ferritin (mL/ng), median (IQR) & $43.5(24.7-87.6)$ \\
\hline \multicolumn{2}{|l|}{ Radiologic investigations, $n(\%)$} \\
\hline Chest X-ray & $129(21.5)$ \\
\hline Chest computed tomography & $23(3.8)$ \\
\hline
\end{tabular}

$\mathrm{SD}$, standard deviation; IQR, interquartile range.

most common age group admitted to the hospital was $>10$ years $(58.3 \%)$, followed by the age group of $\leq 1$ year $(20.8 \%)$. The median length of PICU stay was 7.5 days (Interquartile Ranges: 3.1-15.1) and median length of hospital stay was 8.5 days (Interquartile Ranges: 6.0-14.2). Two (0.3\%) patients died (Table 1). These patients were 8-month-old and 16-year-old boys who had already been diagnosed with arthrogryposis-renal dysfunctioncholestasis (ARC) syndrome and Ewing sarcoma, presented with septic shock and acute respiratory distress syndrome, and stayed in the PICU for 8.4 and 22.0 days, respectively.

Comparing the intervention periods, in accordance with chronologic order, there was a statistically significant increase in the number of daily cases and decreases in the number of asymptomatic cases, contact history with COVID-19 PCR-positive individuals, number of patients from whom laboratory/radiologic tests were obtained, and hospital admission rates $(P<0.05)$. There was no difference in PICU admissions ( $P=0.764)$ (Table 4$)$. Both of the patients who died had arrived at the pediatric emergency department in the third time period. In the second period, we observed a rapidly increasing number of daily new cases, especially in August. These data pointed to an outbreak of COVID-19. Thereafter, there was a slight decrease until September. After September, an increase was observed, being particularly marked from October to November 18, the date when the highest number of daily cases was observed, just 3 days after starting the third period. Thereafter, there was another decrease in the daily number of cases until January 16, 2021 (Figure 1). As the number of cases increased, there was also a parallel increase in the positivity rate of SARS-CoV-2 PCR tests (Figure 2).

During the study period, a total of $10(1.6 \%)$ children were diagnosed with MIS-C, equivalent to $1 / 61$ cases. Among them, 4 $(40.0 \%)$ patients were admitted to the emergency department in the second intervention period, starting from September, and 6 $(60.0 \%)$ in the third intervention period; accordingly, there was an increase in MIS-C cases over time.

\section{DISCUSSION}

COVID-19 is a rapidly evolving pandemic and has had catastrophic effects on global health. Rapid adaptation and pragmatic measures are crucial in dealing with such challenges. ${ }^{10}$ Understanding the characteristics of SARS-CoV-2 infection in the pediatric population and their significance in the ongoing pandemic is vital for guiding healthcare interventions in a country. ${ }^{11}$

Of all patients in our study, $25.0 \%$ were asymptomatic, in accordance with studies from China. ${ }^{9,12}$ Asymptomatic carriage and milder clinical presentation in children may lead to a decreased need for testing, especially in already burdened healthcare systems. Hence, the pediatric population may remain a source of continued transmission, the magnitude of which remains unexplored. ${ }^{13}$ In our study, $76.6 \%$ of the patients had household contact with a COVID-19 PCR-positive individual. History of contact with an individual infected by COVID-19 was reported as a predictor for PCR positivity. ${ }^{14}$ The lower percentage of susceptibility in the pediatric population could be explained by differences in symptomatic infection rates and subsequent issues with case ascertainment. ${ }^{15}$ Household transmission studies found that pediatric cases were usually identified through contact tracing of adults, although some case reports documented transmission from children to adults. ${ }^{16}$ Information about the transmissibility of SARSCoV-2 from child to child is also insufficient.

In a review including 7780 children, frequently encountered symptoms of COVID-19 were reported as fever and cough, ${ }^{17}$ in accordance with our findings. However, infected patients may present with a wide variety of symptoms such as fatigue, myalgia, vomiting, sore throat, headache, or diarrhea. ${ }^{18}$ Among recent data, it was reported that a 45-day-old infant presented with only vomiting in the early stage and gradually progressed to a severe disease. ${ }^{18}$ In our study, moderate, severe, and critical cases had higher percentages of vomiting than mild cases. Thus, it is important to pay attention to symptoms other than fever and cough in suspected cases with an epidemiological history.

The hospitalization rate was reported to be between $5.7 \%$ and $20 \%$, and the PICU admission rate was reported between $0.5 \%$ and $2 \%$ in children. ${ }^{21}$ Cases under the age of 1 year accounted for the highest percentage, with hospitalization rates of $15-62 \% .{ }^{19}$ Our hospitalization rate was $4.0 \%$ and the PICU admission rate was $1.6 \%$. In contrast to the literature, children aged $>10$ years were the most common group for hospital admissions, followed by the age group of $\leq 1$ year in our study. 
TABLE 3. Demographics, Clinical Findings, and Laboratory Results of the Patients According to Clinical Severity Groups

\begin{tabular}{|c|c|c|c|}
\hline Variable & Asymptomatic/Mild, $n=577$ & Moderate/Severe/Critical, $n=23$ & $P$ \\
\hline Male gender, $n(\%)$ & $277(48.0)$ & $19(82.6)$ & .001 \\
\hline Age in years, median (IQR) & $12.0(4.4-15.1)$ & $12.0(2.1-15.0)$ & .757 \\
\hline Underlying disease, $n(\%)$ & $46(8.0)$ & $16(69.6)$ & $<.001$ \\
\hline \multicolumn{4}{|l|}{ Symptoms, $n(\%)$} \\
\hline Fever & $254(44.0)$ & $18(78.3)$ & .030 \\
\hline Cough & $173(30.0)$ & $6(26.1)$ & .268 \\
\hline Fatigue & $118(20.5)$ & $6(26.1)$ & .003 \\
\hline Nausea/vomiting & $17(2.9)$ & $5(21.7)$ & $<.001$ \\
\hline Abnormal chest examination & $6(1.0)$ & $9(39.1)$ & $<.001$ \\
\hline Tachycardia, $n(\%)$ & $4(0.7)$ & $4(17.4)$ & $<.001$ \\
\hline Lymphocyte count $/ \mathrm{mm}^{3}$, median (IQR) & $2200.0(1500.0-3200.0)$ & $1500.0(700.0-2400.0)$ & .007 \\
\hline Lymphopenia, $n(\%)$ & $44(7.6)$ & $11(47.8)$ & .061 \\
\hline Hemoglobin $(\mathrm{g} / \mathrm{dL})$, mean $\pm \mathrm{SD}(\min -\max )$ & $13.1 \pm 1.4(7.7-16.5)$ & $11.8 \pm 2.3(7.3-126.4)$ & .003 \\
\hline Platelet count $/ \mathrm{mm}^{3}$, median (IQR) & $267000.0(232000.0-318000.0)$ & $171000.0(93000.0-276000.0)$ & $<.001$ \\
\hline Prothrombin time (s), median (IQR) & $11.9(11.5-12.3)$ & $12.7(12.0-13.4)$ & $<.001$ \\
\hline International normalized ratio, median (IQR) & $1.0(0.9-1.0)$ & $1.0(1.0-1.2)$ & $<.001$ \\
\hline D-dimer $(\mu \mathrm{g} / \mathrm{mL})$, median (IQR) & $0.4(0.3-0.8)$ & $1.4(0.5-2.7)$ & $<.001$ \\
\hline D-dimer $>0.55 \mu \mathrm{g} / \mathrm{mL}, n(\%)$ & $48(8.3)$ & $17(73.9)$ & .004 \\
\hline C-reactive protein $(\mathrm{mg} / \mathrm{L})$, median (IQR) & $2.9(0.8-8.6)$ & $8.0(3-174.0)$ & .009 \\
\hline C-reactive protein $>5 \mathrm{mg} / \mathrm{L}, n(\%)$ & $59(10.2)$ & $13(56.5)$ & .039 \\
\hline Procalcitonin (ng/mL), median (IQR) & $0.04(0.02-0.08)$ & $0.21(0.10-0.58)$ & $<.001$ \\
\hline Procalcitonin $>0.05 \mathrm{ng} / \mathrm{mL}, n(\%)$ & $59(9.2)$ & $13(56.5)$ & .019 \\
\hline Troponin (mg/L), median (IQR) & $5.0(5.0-5.0)$ & $8.6(5.4-43.7)$ & $<.001$ \\
\hline Troponin $>42.8 \mathrm{mg} / \mathrm{L}, n(\%)$ & $2(0.3)$ & $4(17.4)$ & .014 \\
\hline Ferritin (mL/ng), median (IQR) & $36.0(22.5-62.4)$ & $172.0(66.5-921.5)$ & $<.001$ \\
\hline
\end{tabular}

$\mathrm{SD}$, standard deviation; IQR, interquartile range.

A sex difference in mortality was suggested in the literature. In one analysis, $57 \%$ of the pediatric patients were male, and similarly, slightly more male than female patients were affected in China. ${ }^{9}$ In our study, male patients were hospitalized more and they also had a higher PICU admission rate. While they also had underlying diseases, both of our patients who died were male. It was reported that $83 \%$ of children who required PICU admission had underlying diseases. ${ }^{20}$ In our study, moderate/severe/critical patients were also more likely to be male, and had a higher percentage of chronic illnesses. In previous studies of 2141 and 2228 children with confirmed COVID-19 disease, severe and critical disease was reported at a rate of $3.1 \%$ and $0.6 \% .^{9,21}$ In accordance with previous data,

TABLE 4. Demographics, Laboratory and Radiologic Tests, and Prognosis of the Patients According to Intervention Periods

\begin{tabular}{|c|c|c|c|c|}
\hline Variable & First Period $(n=30)$ & Second Period $(n=290)$ & Third Period $(n=280)$ & $P$ \\
\hline Number of daily cases (cases/day) median (IQR) & $1.0(1.0-2.0)$ & $2.0(1.0-4.0)$ & $4.0(2.0-6.5)$ & $<.001$ \\
\hline Asymptomatic cases, $n(\%)$ & $12(40.0)$ & $91(31.4)$ & $43(15.4)$ & $<.001$ \\
\hline Contact with a COVID-19 PCR-positive individual, $n(\%)$ & $24(80.0)$ & $226(77.9)$ & $191(68.2)$ & .019 \\
\hline Laboratory tests, $n(\%)$ & $17(56.7)$ & $117(40.3)$ & $56(20.0)$ & $<.001$ \\
\hline Radiologic investigations, $n(\%)$ & $19(63.3)$ & $76(26.2)$ & $42(15.0)$ & $<.001$ \\
\hline Moderate/severe/critical cases, $n(\%)$ & $3(10.0)$ & $7(2.4)$ & $13(4.6)$ & .163 \\
\hline Hospital admissions, $n(\%)$ & $4(13.3)$ & $11(3.8)$ & $9(3.2)$ & .026 \\
\hline PICU admissions, $n(\%)$ & $0(0.0)$ & $5(1.7)$ & $5(1.8)$ & .764 \\
\hline Mortality, $n(\%)$ & $0(0.0)$ & $0(0.0)$ & $2(0.7)$ & - \\
\hline
\end{tabular}

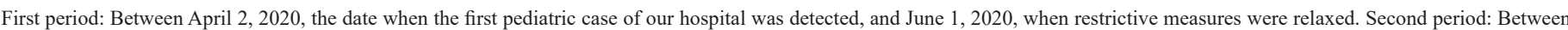
June 1, 2020 and November 15, 2020, when restrictive measures were re-implemented. Third period: Between November 15, 2020 and January 16, 2021.

PICU, pediatric intensive care unit; IQR, interquartile range. 


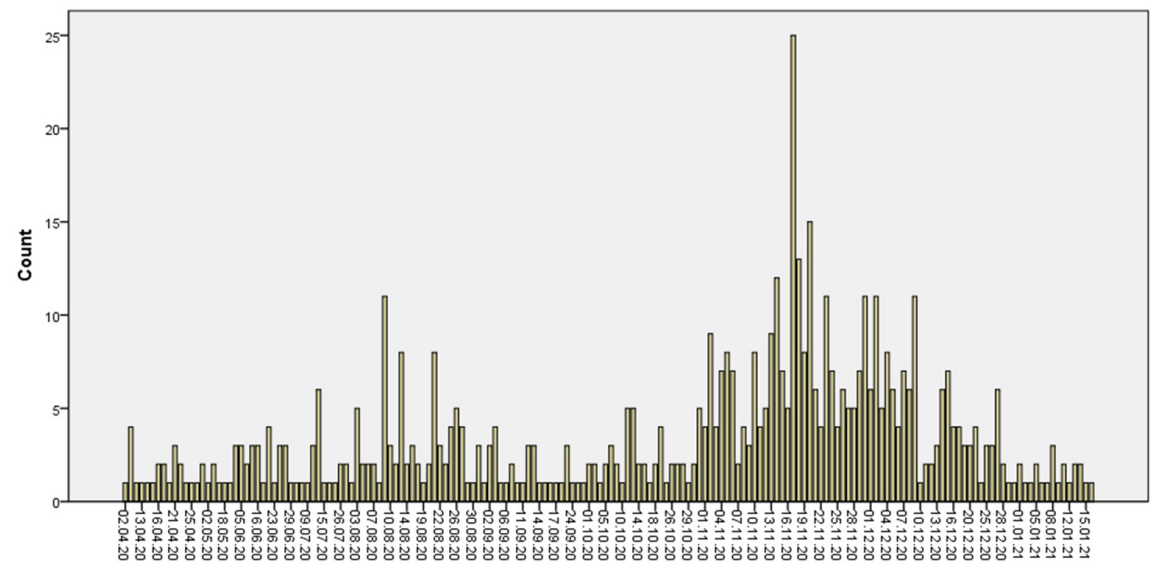

FIG. 1. Number of daily cases during the study period.

our severe/critical cases represented 1.5\% of all COVID-19 PCRpositive cases.

In a study from China, typical laboratory findings of children with COVID-19 were reported as lymphopenia, leukopenia, and elevated creatine kinase and procalcitonin levels. ${ }^{22}$ On the other hand, white blood cell or lymphocyte counts were found normal in some pediatric studies. ${ }^{18} \mathrm{We}$ also found no specific laboratory abnormalities that affected the majority of our cases. Our data support the prevalent activation of the coagulation cascade in children with severe presentations; this is significant as it is a predictor of cases being severe/critical according to clinical severity. ${ }^{23}$ In a review by Moutchia et al., severe/critical cases were reported to have increased neutrophil counts and acute phase reaction markers of CRP, erythrocyte sedimentation rate, and serum ferritin, as well as decreased levels of albumin. ${ }^{24}$ In our study, CRP, procalcitonin, PT, D-dimer, INR, troponin, and ferritin levels were higher in moderate/severe/critical cases.

There were 10 cases of MIS-C during our study period. In a study from the United States, the rate was estimated to be about
1/161 among COVID-19 patients under the age of 21 years. ${ }^{11}$ In our study, the rate was higher, at $1 / 61$ cases. This could due to the fact that our population was under the age of 18 years, as MIS-C might be more common at younger ages.

As the number of cases increased, there was also a parallel increase in the positivity rate of SARS-CoV-2 PCR tests in our study. We observed a rapidly increasing number of daily new cases in the second period, especially in August. These data pointed to an outbreak of COVID-19. Thereafter, there was a slight decrease until September. From September, an increase was observed, which was particularly marked from October to November 18 , the date when the highest number of daily cases was observed, just 3 days after starting the third period. There was then a decrease in the daily number of cases until January 16, 2021. Most studies have suggested that the latency period of COVID-19 is 7-14 days. ${ }^{25}$ The decrease in the third period started 3 days after strict measures were implemented, earlier than the reported latency of COVID-19.

Chronologically, there was a decrease in contact history with a COVID-19 PCR-positive individual, the number of cases for which

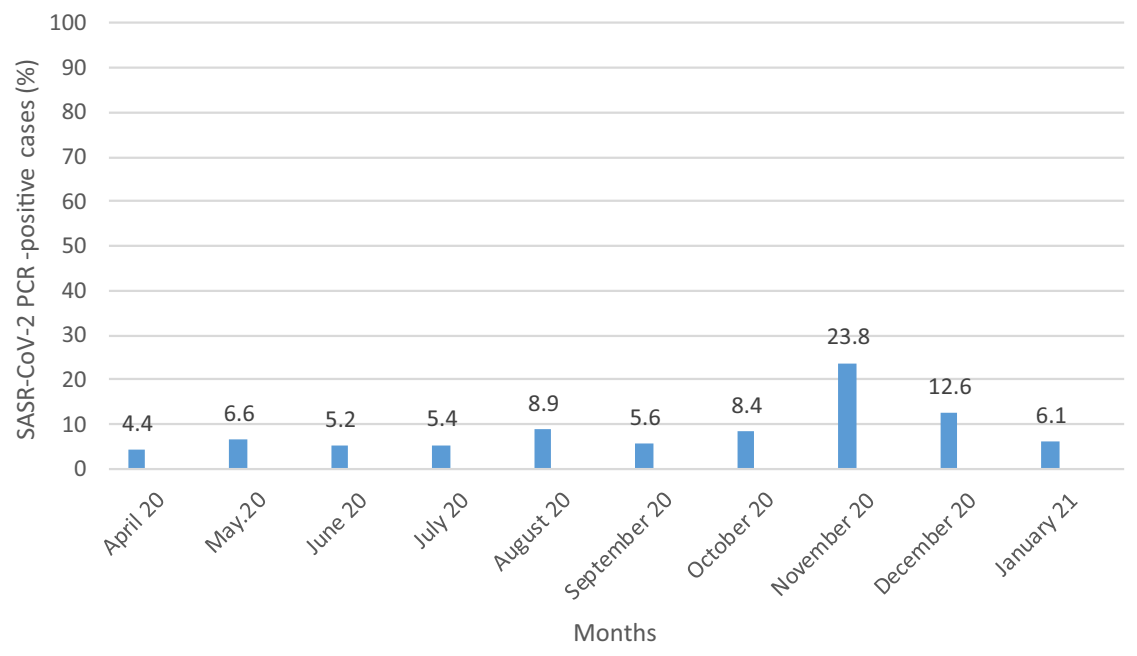

FIG. 2. Alterations in the percentage of pediatric SARS-CoV-2 PCR positivity during the study period. 
laboratory/radiologic tests were obtained, and hospital admission rates in our study. This could be related to having obtained better and more clear information about the natural course of the disease over time.

Our study reveals that the implementation of strict intervention measures seems to have been effective in containing the spread of COVID-19. The issues of childcare and reopening of schools are still being debated, due to the uncertainty of whether children are efficient transmitters of COVID-19. ${ }^{26}$ Children appear to be far less likely to be infected and more likely to be asymptomatic. ${ }^{27} \mathrm{On}$ the other hand, because viral loads may be similar in symptomatic and asymptomatic COVID-19 carriers, including children, there may be a high risk for transmission through asymptomatic children. ${ }^{28,29}$ Studies which have examined pediatric transmission risks are mostly limited by small sample sizes and were conducted during school closures, when the possibility of transmission through children was absolutely limited. ${ }^{30}$

In conclusion, the majority of the cases presented here were asymptomatic or had a mild clinical course. The presence of chronic diseases, pathological respiratory system examinations, and procalcitonin levels of $>0.05 \mathrm{ng} / \mathrm{mL}$ were identified as predictors of cases being moderate, severe, or critical in terms of clinical severity. Strict interventional measures seem to have been effective in containing the spread of COVID-19.

Ethics Committee Approval: Ethics committee approval was received for this study from the Local Ethics Committee of Dokuz Eylül University, School of Medicine (approval number: 2020/12-27).

Patient Consent for Publication: This was a retrospective study and all patients were deidentified. So, there was no need for written informed consent.

Data-sharing Statement: The data that support the findings of this study are available from the corresponding author upon reasonable request.

Author Contributions: Concept - M.D.; Design - N.Ş., M.D.; Supervision - D.Y., Ö.A., A.A.S; Materials - A.Ç.G., H.K.A., Ş.Ö.A., İ.C.E., Ö.A., A.A.S.; Data Collection and/or Processing - N.Ş., A.Ç.G., H.K.A., N.B., Ş.Ö.A., İ.C.E., Ö.A., A.A.S.; Analysis and/or Interpretation - N.Ş., D.Y., A.Ç.G., H.K.A., N.B., Ş.Ö.A., Ö.A., A.A.S.; Literature Review - N.Ş., M.D., D.Y., A.Ç.G., H.K.A., N.B., Ş.Ö.A., İ.C.E.; Writing - N.Ş.; Critical Review - M.D., D.Y., N.B.

Conflict of Interest: The authors have no conflicts of interest to declare.

Funding: The authors declared that this study has received no financial support.

\section{REFERENCES}

1. Paules CI, Marston HD, Fauci AS. Coronavirus infections-more than just the common cold. JAMA. 2020;323(8):707-708. [CrossRef]

2. Wu F, Zhao S, Yu B, et al. A new coronavirus associated with human respiratory disease in China. Nature. 2020;579(7798):265-269. [CrossRef]

3. Demirbilek Y, Pehlivantürk G, Özgüler ZÖ, Alp Meşe E. COVID-19 outbreak control, example of ministry of health of Turkey. Turk J Med Sci. 2020;50;SI1(SI-1):489-494. [CrossRef]

4. Posfay-Barbe KM, Wagner N, Gauthey M, et al. COVID-19 children and the dynamics of infection in families. Pediatrics. 2020;146(2):e20201576. [CrossRef]

5. Yılmaz K, Gozupirinççioğlu A, Aktar F, et al. Evaluation of the novel coronavirus disease in Turkish children: Preliminary outcomes. Pediatr Pulmonol. 2020;55(12):3587-3594. [CrossRef]

6. Verma S, Lumba R, Dapul HM, et al. Characteristics of hospitalized children with SARS-CoV-2 in the New York City metropolitan area. Hosp Pediatr. 2021;11(1):7178. [CrossRef]
7. European Centre for Disease Prevention and Control. Rapid risk assessment: paediatric inflammatory multisystem syndrome and SARS-CoV-2 infection in children. https://www.ecdc.europa.eu/en/publications-data/paediatric-inflammatory-multisys tem-syndrome-and-sars-cov-2-rapid-risk-assessment; 2020. Solna, Sweden: ECDC.

8. American College of Surgeons Committee on Trauma. Advanced Trauma Life Support (ATLS) Student Course Manual. 9th ed. Chicago, IL: American College of Surgeons; 2012.

9. Dong Y, Mo X, Hu Y, et al. Epidemiology of COVID-19 among children in China Pediatrics. 2020;145(6):e20200702. [CrossRef]

10. Micallef S, Piscopo TV, Casha R, et al. The first wave of COVID-19 in Malta; a national cross-sectional study. PLOS ONE. 2020;15(10):e0239389. [CrossRef]

11. Maltezou HC, Magaziotou I, Dedoukou X, et al. Children and adolescents with SARS-CoV-2 infection: epidemiology, clinical course and viral loads. Pediatr Infect Dis J. 2020;39(12):e388-e392. [CrossRef]

12. Zhen-Dong Y, Gao-Jun Z, Run-Ming J, et al. Clinical and transmission dynamics characteristics of 406 children with coronavirus disease 2019 in China: a review. $J$ Infect. 2020;81(2):e11-e15. [CrossRef]

13. Jahangir M, Nawaz M, Nanjiani D, Siddiqui MS. Clinical manifestations and outcomes of COVID-19 in the paediatric population: a systematic review. Hong Kong Med J. 2021;27(1):35-45. [CrossRef]

14. Arslan G, Aktürk H, Duman M. Clinical characteristics of pediatric COVID-19 and predictors of PCR positivity. Pediatr Int. 2021. [CrossRef]

15. Mehta NS, Mytton OT, Mullins EWS, et al. SARS-CoV-2 (COVID-19): what do we know about children? A systematic review. Clin Infect Dis. 2020;71(9):2469-2479. [CrossRef]

16. Jiehao C, Jin X, Daojiong L, et al. A case series of children with 2019 novel coronavirus infection: Clinical and epidemiological features. Clin Infect Dis. 2020;71(6):15471551. doi:10.1093/cid/ciaa198.

17. Hoang A, Chorath K, Moreira A, et al. COVID-19 in 7780 pediatric patients: A systematic review. EClinicalmedicine. 2020;24:100433. [CrossRef]

18. Qiao MY, Chen N, Zou X, et al. How to early identify and prevent the SARS-CoV-2 infection in children for families? Front Pediatr. 2020;8:542. [CrossRef]

19. Tiruneh FT. Clinical profile of Covid-19 in children, review of existing literatures. Pediatr Health Med Ther. 2020;11:385-392. [CrossRef]

20. Shekerdemian LS, Mahmood NR, Wolfe KK, et al. Characteristics and outcomes of children with coronavirus disease 2019 (COVID-19) infection admitted to US and Canadian pediatric intensive care units. JAMA Pediatr. 2020;174(9):868-873. [CrossRef]

21. Panahi L, Amiri M, Pouy S. Clinical characteristics of COVID-19 infection in newborns and pediatrics: A systematic review. Arch Acad Emerg Med. 2020;8(1):e50.

22. Qiu H, Wu J, Hong L, et al. Clinical and epidemiological features of 36 children with coronavirus disease 2019 (COVID-19) in Zhejiang, China: An observational cohort study. Lancet Infect Dis. 2020;20(6):689-696. [CrossRef]30198-5)

23. Desai A, Mills A, Delozier S, et al. Pediatric patients with SARS-CoV-2 infection: Clinical characteristics in the United States from a large global health research network. Cureus. 2020;12(9):e10413. [CrossRef]

24. Moutchia J, Pokharel P, Kerri A, Uchai S, Nji M. Clinical laboratory parameters associated with severe or critical novel coronavirus disease 2019 (COVID-19): A systematic review and meta-analysis. PLOS ONE. 2020;15(10):e0239802. [CrossRef]

25. Streng A, Hartmann K, Armann J, Berner R, Liese JG. COVID-19 in hospitalized children and adolescents. Monatsschr Kinderheilkd. 2020:1-12. [CrossRef]

26. Gilliam WS, Malik AA, Shafiq M, et al. COVID-19 transmission in US child care programs. Pediatrics. 2021;147(1):e2020031971. [CrossRef]

27. Wu Z, McGoogan JM. Characteristics of and important lessons from the coronavirus disease 2019 (COVID-19) outbreak in China: Summary of a report of 72314 cases from the Chinese Center for Disease Control and Prevention. JAMA. 2020;323(13):1239-1242. [CrossRef]

28. Zou L, Ruan F, Huang M, et al. SARS-CoV-2 viral load in upper respiratory specimens of infected patients. $N$ Engl J Med. 2020;382(12):1177-1179. doi:10.1056/ NEJMc2001737.

29. Yonker LM, Neilan AM, Bartsch Y, et al. Pediatric severe acute respiratory syndrome coronavirus 2 (SARS-CoV-2): Clinical presentation, infectivity, and immune responses. J Pediatr. 2020;227:45-52.e5. [CrossRef]

30. Park YJ, Choe YJ, Park O, et al. Contact tracing during coronavirus disease outbreak, South Korea, 2020. Emerg Infect Dis. 2020;26(10):2465-2468. [CrossRef] 